\title{
Anomalous left coronary artery originating from the pulmonary artery
}

\author{
*Prabhas Prasun Giri ${ }^{1}$, Agnisekhar Saha ${ }^{2}$ \\ Sri Lanka Journal of Child Health, 2015; 44(4): 231-233
}

(Key words: Anomalous origin of the left coronary artery from the pulmonary artery, ALCAPA, sepsis)

\section{Introduction}

Cardiac disorders such as coarctation of aorta, aortic stenosis and anomalous origin of the left coronary artery from pulmonary artery (ALCAPA) can mimic sepsis and septic shock early in the life $^{1,2}$. Prompt identification of these non-infectious causes and rapid treatment can be lifesaving. Here our index case was a case of ALCAPA and initially she was thought to be having sepsis.

\section{Case report}

A 49 day old female baby was admitted with a history of poor feeding, refusal to suck and excessive lethargy for last 2 days followed by respiratory distress and oliguria. On admission, the baby had severe respiratory distress, tachycardia and weak femoral pulses. The capillary refill time was prolonged. Chest auscultation revealed good bilateral air entry and audible heart sounds without any evidence of gallop rhythm. Liver was palpable $3 \mathrm{~cm}$ below the right costal margin. The baby was immediately shifted to the paediatric intensive care unit where she was intubated and ventilated due to increased respiratory efforts, falling saturation and metabolic derangements. A provisional diagnosis of sepsis was made and the baby was started on intravenous cefotaxime. Chest $\mathrm{x}$-ray revealed bilateral whiteout lungs (Figure 1) and arterial blood gases $(\mathrm{ABG})$ revealed a mixed acidosis.

The total leucocyte count was $6,500 / \mathrm{cu} \mathrm{mm}$ (N58, L37), the platelet count $360,000 / \mathrm{cu} \mathrm{mm}$, and the haemoglobin level $9.6 \mathrm{~g} \%$. The C-reactive protein was normal. The prothrombin time was 38.5 seconds and the activated partial thromboplastin time 61.4 seconds. The blood urea was $42 \mathrm{mg} / \mathrm{dl}$

${ }^{1}$ RMO cum Clinical Tutor, Institute Of Child Health, ${ }^{2}$ Consultant Paediatric Intensivist, Fortis Hospital, Kolkata, India

*Correspondence: dr.prabhas@yahoo.co.in (Received on 23 June 2014: Accepted after revision on 22 August 2014)

The authors declare that there are no conflicts of interest
Open Access Article published under the Creative

Commons CC-BY-NC-ND Licence.

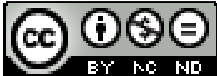

and the serum creatinine $1.1 \mathrm{mg} / \mathrm{dl}$. The serum electrolytes were normal. The aspartate transaminase level was 402 IU and the alanine transaminase level 160 IU.

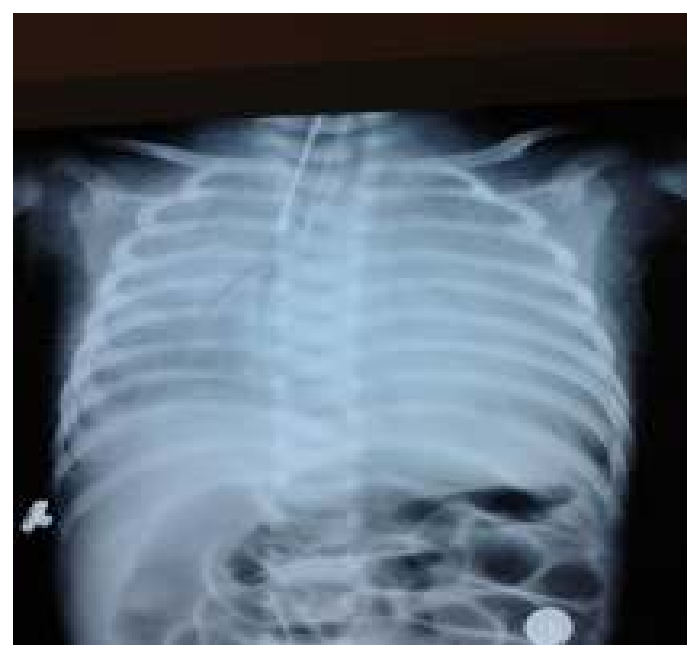

Figure 1: CXR showing bilateral whiteout lungs

After one hour of mechanical ventilation the blood pressure started falling and the perfusion worsened. Dopamine and dobutamine infusions were added. Due to persistent hypotension, features of poor perfusion and metabolic acidosis, echocardiography was done and this revealed a dilated left atrium and ventricle, severe systolic dysfunction with a left ventricular ejection fraction of $20 \%$ with moderate mitral regurgitation and classical anomalous left coronary artery from pulmonary artery (ALCAPA) with reversal of flow. A 12 lead electrocardiogram (ECG) revealed ST and $\mathrm{T}$ wave changes with deep $\mathrm{Q}$ waves in chest leads (Figure 2). 


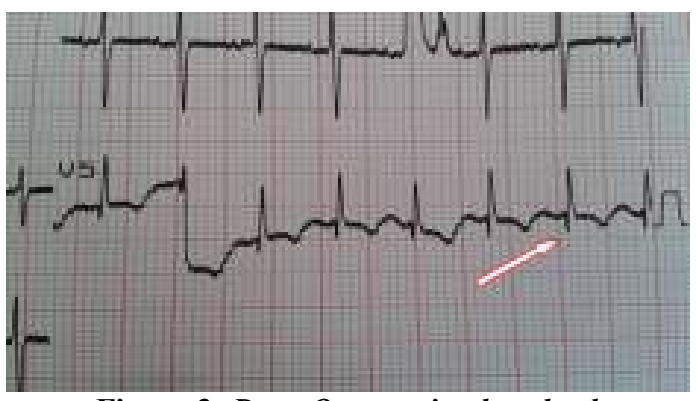

Figure 3: Deep $Q$ waves in chest leads

A final diagnosis of ALCAPA was made. She was stabilised with inotropes and frusemide and transferred to a regional cardiology centre for further management.

\section{Discussion}

ALCAPA is a rare congenital abnormality affecting 1 in 300,000 live births ${ }^{3}$. It results in the "coronary steal" phenomenon, in which a left-to-right shunt leads to abnormal left ventricular perfusion and is the commonest cause of myocardial ischaemia and infarction in children ${ }^{4}$. In the neonatal period, the baby is asymptomatic because there is anterograde flow of desaturated blood from the pulmonary artery to the left coronary artery. As pulmonary arterial pressure drops, the combination of low flow and desaturated blood causes myocardial ischaemia, especially during exertion. Collateral vessels develop between the right and left coronary arteries. Further decreases in pulmonary arterial pressure result in reversal of flow, as the left coronary artery drains from the right coronary artery, through collaterals, into the pulmonary artery. This is known as myocardial steal; hence the nickname of $\mathrm{Al}$ Capone of coronary vessels ${ }^{5}$.

Onset of symptoms usually occurs about 8 weeks after birth. Babies usually present with paroxysms of irritability, excessive crying and overall pictures of distress correlating with episodes of angina. Rarely, it can mimic the soft signs of sepsis like poor feeding, lethargy like our index case. Features of shock like poor perfusion, tachycardia, weak femoral pulse, persistent hypotension and oliguria also occurs due to cardiac failure ${ }^{6}$. Significant heart murmur is usually absent, with a rare exception of a heart murmur of mitral regurgitation secondary to myocardial infarction. ECG shows an anterolateral myocardial infarction pattern consisting of abnormally deep and wide $\mathrm{Q}$ waves, inverted $\mathrm{T}$ waves and ST segment shifts in leads I and aVL and the precordial leads ${ }^{7}$.

Chest radiography may demonstrate left ventricular hypertrophy and dilation secondary to chronic myocardial ischaemia. Main differential diagnosis at this stage is cardiomyopathy, which is excluded on echocardiography. Bilateral white out lungs, as in our index case, are suggestive of cardiogenic pulmonary oedema. Echocardiography shows the anomalous left coronary artery with Doppler flow confirming the reversal of flow ${ }^{8}$. Coronary artery angiography will additionally demonstrate dilated tortuous vessels and reversal of flow into the pulmonary artery on delayed images. CT coronary angiography has the benefit of being non-invasive and will also demonstrate the origin of the left coronary artery from the pulmonary artery.

Medical management involves treatment of cardiac failure and once patients are stable surgical correction to re-establish a two-coronary artery perfusion system is the treatment of choice. Among the many methods available, intrapulmonary tunnel operation (Taeuchi Repair) is the most popular one $^{9}$. But in critically ill infants, palliative surgery like ligation of the anomalous left coronary artery close to its origin from the PA may be performed to prevent steal into the PA.

\section{References}

1. Woodward GA, Mahle WT, Forkey HC, Wernovsky G, Rhodes LA. Sepsis, septic shock, acute abdomen? The ability of cardiac disease to mimic other medical illness. Pediatric Emergency Care 1996; 12(4): 31723.

http://dx.doi.org/10.1097/0000656519960800 0-00021

2. Mahle WT. A dangerous case of colic: Anomalous left coronary artery presenting with paroxysms of irritability. Pediatric Emergency Care 1998; 14: 24-7.

http://dx.doi.org/10.1097/0000656519980200 0-00007

PMid: 9516627

3. Pena E, Nguyen ET, Merchant N, Dennie C. ALCAPA syndrome: Not just a paediatric disease. Radiographics 2009; 29:553-65. http://dx.doi.org/10.1148/rg.292085059 PMid: 19325065

4. Lardhi AA. Anomalous origin of left coronary artery from pulmonary artery: A rare cause of myocardial infarction in children. Journal of Family Community Medicine 2010; 17:113-6. http://dx.doi.org/10.4103/1319-1683.74319 PMid: 21359020 PMCid:PMC3045108

5. Wesselhoeft H, Fawcett JS, Johnson AL. Anomalous origin of the left coronary artery from the pulmonary trunk: its clinical 
spectrum, pathology, and pathophysiology, based on a review of 140 cases with seven further cases. Circulation 1968; 38:403- 25.

http://dx.doi.org/10.1161/01.CIR.38.2.403

PMid: 5666852

6. Cowles RA, Berdon WE. Bland-WhiteGarland syndrome of anomalous left coronary artery arising from the pulmonary artery: A historical review. Pediatric Radiology 2007; 37:890-5.

http://dx.doi.org/10.1007/s00247-007-0544-8

PMid: 17607572

7. Brotherton H, Phillip RK. Anomalous left coronary artery from pulmonary artery (ALCAPA) in infants: a 5 year review in a defined birth cohort. European Journal of Pediatrics 2008; 167:43-6.

http://dx.doi.org/10.1007/s00247-007-0544-8

PMid: 17607572

8. Karolczak MA, Wieteska J, Bec L, Madry W. Anomalous origin of the left coronary artery (LCA) from pulmonary trunk (Bland-WhiteGarland syndrome) with systemic collateral supply to LCA. Medical Science Monitor 2001; 7:755-8.

PMid: 11433207
9. Dodge-Khatami A, Mavroudis C, Backer CL. Anomalous origin of the left coronary artery from the pulmonary artery: collective review of surgical therapy. Annals of Thoracic Surgery 2002; 74:946-55. http://dx.doi.org/10.1016/S00034975(02)0363 3-0 